\title{
An In Vitro Evaluation of Remineralization Potential of Functionalized Tricalcium Phosphate Paste and CPP-ACPF on Artificial White Spot Lesion in Primary and Permanent Enamel
}

\author{
Neha Bhadoria ${ }^{1}$, Mohit K Gunwal ${ }^{2}$, Rinky Kukreja ${ }^{3}$, Satish Maran ${ }^{4}$, Shashikiran N Devendrappa ${ }^{5}$, Shilpy Singla ${ }^{6}$
}

\begin{abstract}
Aim: Investigation and evaluation of remineralization potential of functionalized tricalcium phosphate paste (fTCP) and casein phosphopeptideamorphous calcium phosphate (CPP-ACPF) paste on artificially created white spot lesion on human primary and permanent enamel through scanning electron microscopy and microhardness assessment.

Materials and methods: Sixty freshly extracted primary and permanent teeth were selected and artificial white spot lesion were created by using standardized demineralizing solution. Remineralization was carried out using the test pastes. The assessment of demineralization and remineralization was done through a scanning electron microscope and microhardness assessment.

Results: Among the three groups, fTCP shows significantly higher increase in mean microhardness $(p<0.001)$ through ANOVA and the LSD post hoc test when compared to CPP-ACPF and control group. Also, the unpaired $t$-test showed that mean change in microhardness in permanent teeth was significantly higher than primary teeth in different time intervals for both experimental groups. Surface morphology was assessed through a scanning electron microscope.

Conclusion: Based on the results of the current study, f-TCP showed comparatively more remineralization potential than CPP-ACP with fluoride. Keywords: Microhardness, Minimal invasive dentistry, Permanent, Primary dentition, Scanning electron microscope. International Journal of Clinical Pediatric Dentistry (2020): 10.5005/jp-journals-10005-1813
\end{abstract}

\section{INTRODUCTION}

The earliest phases of decay or demineralization occurring in tooth are identified as incipient lesions. They are active lesions confined to the enamel and are sometimes referred as smooth surface caries or white spot lesions. ${ }^{1}$ These lesions presets with potential of being upturned, arrested, or continuing to cavitations depending upon clinical condition provided, including diet, use of fluoride, and the buffering action of saliva. ${ }^{2}$ For noncavitated lesions, remineralization presets as a natural repair process. This event of remineralization for the renovation of a new surface on already existing crystal remnants in subsurface lesions occurs via fluoride-assisted calcium and phosphate ions deposition. Also these newly remineralized crystals are less prone toward acid solubility than the original mineral content of tooth. ${ }^{1}$

Nowadays, various novel calcium phosphate-based materials are developed and clinically accessible for remineralization of tooth in the deficiency of fluoride, such as bioactive glass, amorphous calcium phosphate, and milk-derived protein complexes. ${ }^{3}$ These nonfluoridated remineralizing agents create supersaturated state for calcium and phosphate ions for remineralization in absence of fluoride. However, when there is an adequate availability of calcium and phosphate ions together with the fluoride ions, it is revealed that considerable amount of remineralization of enamel and underlying dentin lesions can be attained.' One of the initially available agents for remineralization with commercial availability containing bioactive agent is CPP-ACP (Tooth Mousse, GC International, Itabashi-ku, Tokyo, Japan). Also GC Tooth Mousse Plus (CPP-ACPF) has been introduced. It contains CPP-ACP and fluoride
${ }^{1}$ Department of Pediatric Dentistry, Index Institute of Dental Sciences, Indore, Madhya Pradesh, India

${ }^{2}$ Department of Conservative Dentistry and Endodontics, VSPM's Dental College and Research Center, Maharashtra, Nagpur, India

${ }^{3}$ Department of Pedodontics, Pacific Dental College and Research Center, Udaipur, Rajasthan, India

${ }^{4}$ Department of Pedodontics and Preventive Dentistry, Peoples Dental Academy, Bhopal, Madhya Pradesh, India

${ }^{5}$ Department of Pedodontics, Krishna Dental College, Karad, Maharashtra, India

${ }^{6}$ Department of Pedodontics and Preventive Dentistry, Rishiraj Dental College, Bhopal, Madhya Pradesh, India

Corresponding Author: Neha Bhadoria, Department of Pediatric Dentistry, Index Institute of Dental Sciences, Indore, Madhya Pradesh, India, Phone: +91 9752826855, e-mail: bhadorianeha01@ gmail.com

How to cite this article: Bhadoria N, Gunwal MK, Kukreja R, et al. An In Vitro Evaluation of Remineralization Potential of Functionalized Tricalcium Phosphate Paste and CPP-ACPF on Artificial White Spot Lesion in Primary and Permanent Enamel. Int J Clin Pediatr Dent 2020;13(6):579-584.

Source of support: Nil

Conflict of interest: None

in which the level of fluoride is $0.2 \%$ or $900 \mathrm{ppm}$. CPP-ACP when added with fluoride provides with synergistic outcome on early carious lesions remineralization processes. Elsayad reported the 
similar findings regarding enamel remineralization when CPP-ACP with fluoride was tested. ${ }^{4}$

More recently, a new product was launched as Clinpro Tooth Creme has been introduced, which contains functionalized tricalcium phosphate with 950 ppm of fluoride. While manufacturing the product, placement of a protective barrier around calcium particles is ensured so as allowing its coexistence with the fluoride ions. Advantages of this product are unlike other calcium-based additives; only low levels of functionalized TCP are needed to produce strong, acid-resistant mineral nucleation without negatively affecting fluoride's proven benefits. ${ }^{5}$

A wide range of alternatives are available for in vitro assessment of demineralization and remineralization processes, which includes direct (e.g., microradiography) and indirect (e.g., iodide permeability) methods for the assessment of mineral gain and loss in the tooth structure. Scanning electron microscope (SEM) is extensively explored for evaluation of tooth structure changes owing to extrinsic factors. ${ }^{6}$ The SEM analysis provides with crucial data concerning the processed sample, which include external texture, chemical build-up, crystalline structure, and also material basic structural orientation. A SEM has a larger depth of field providing more of specimen to be in focus at one time; also higher resolution allows examination of closely spaced specimens magnified at much higher levels. Easy and rapid sample preparations for the SEM analysis provided with added benefits. ${ }^{7}$ Surface microhardness indentation used for demineralization and remineralization studies provides with a relatively simple, nondestructive, and rapid method. A relationship of enamel hardness values with mineral content of the tissue in a weight basis exists. ${ }^{8}$

Earlier studies to compare the remineralization potential of white-spot enamel lesions by Tooth Mousse Plus and functionalized tricalcium phosphate have been done on permanent teeth. But those comparing their remineralization potential on primary teeth are not yet being done. In view of the above consideration, the present study is designed to investigate the remineralization potential of CPP-ACPF paste and functionalized tricalcium phosphate paste (fTCP) on artificially created white spot lesion in human primary and permanent enamel through scanning electron microscopy and microhardness assessment.

\section{Materials and Methods \\ Treatment Group}

Study design consisted entirely of 60 enamel specimens containing 30 primary and 30 permanent teeth. Samples were randomly divided into two subgroups. (1) Experimental group $(n=20)$. It was divided into two subgroups: CPP-ACPF $(n=10)$ and f-TCP $(n=10)$. (2) Control group $(n=10)$, which was artificial saliva. All the samples were subjected to demineralization remineralization cycle and evaluated through SEM and the surface microhardness test.

\section{Selection of Teeth}

The sample was prepared from freshly extracted primary and permanent anterior teeth ( $n=30$ each group). Teeth were inspected for cracks, hypoplasia, or any white spot lesion under light microscope (10x) (Inea Olympus Pvt. Ltd., New Delhi). Then specimen was disinfected and stored in formalin., ${ }^{9,10}$

\section{Specimen Preparation}

The $4 \times 4 \times 2 \mathrm{~mm}$ dimensional enamel blocks obtained from the labial surface of the tooth sample were mounted in mold with epoxy resin exposing $4 \times 4 \mathrm{~mm}$ of the enamel surface. The labial enamel surfaces was wet polished with no. 800, 1000, and 1200 grit Sic paper, followed by diamond pastes $(3 \mu \mathrm{m}$ and $1 \mu \mathrm{m})$ (Sprint Saeshin Precision Ind.Co., Korea). The smooth surfaces was then examined under light microscope using 100x objective lens in order to evaluate glassy and transparent appearance of enamel surfaces. ${ }^{11,12}$

\section{White Spot Lesion Formation}

Specimens were rinsed using distilled water and then immersed in carbopol-lactic acid solution containing vials (Sigma-Aldrich chemistry 181285-5G), which were partially saturated with hydroxyapatite (Sigma Aldrich chemistry MKBD 1322) and pH was maintained at 5.0. These vials were then loaded into an incubator (REMI $2 \mathrm{MLH}$ ) at $37^{\circ} \mathrm{C}$ to establish "white-spot" (noncavitated) lesions. Specimens were removed from the solution after 36 hours of sample immersion, then deionized water was used for rinsing (Ultra-Pure, Organo-Biotech Laboratories). Microhardness indenter (M/s Leica Germany) was used to measure the baseline Vickers microhardness (200 gf, 15 seconds dwell time). Specimens with mean Vickers hardness numbers (VHN) between 25 and 50 were selected and divided into three groups. ${ }^{13,14}$

\section{In Vitro pH Cycling Model}

Daily for a total of 10 days the following protocol was followed, which includes two sets of 2-minute treatment periods performed with an hour difference in the morning, followed by one 4-hour carbopol-lactic acid challenge, and finally two additional 2-minute treatment periods in the afternoon. Microhardness levels were measurements after the 5 days of cycling. Each treatment procedure contained use of toothpaste diluted threefold with DI water. To mimic the clinically relevant condition, artificial saliva was used for specimens immersion between the daily treatments and acid challenge. Magnetic agitation at $300 \mathrm{rpm}$ was used for treatment and saliva system, while the acid challenge was static. Daily four fresh treatment slurries and carbopol-lactic acid solution were used. Artificial saliva solution changed once daily after the third treatment. $^{13,14}$

\section{Assessment of Sample}

Samples were assessed for microhardness using VHN and for surface morphology using SEM.

\section{Microhardness}

The specimen was fixed on to the microhardness tester for VHN (M/s Leica Germany). Each enamel specimen was impressed with loads of $200 \mathrm{gf}, 15$ seconds dwell time. The average of three indentations was taken to avoid discrepancy since the enamel surface has a curvature. The baseline observations were made in each group $(n=5)$ after formation of artificial carious lesion (baseline microhardness) and at 5 and 10 days of demineralization-remineralization phase. The change in VHN was determined as the difference between the 5 or 10 days and baseline values. . $^{3,14}$

\section{Surface Morphology}

The specimens from all the three groups were analyzed using SEM. The samples were examined during the pretreatment phase, 
after creating artificial caries lesion and at the end of 10 days of the demineralization-remineralization cycle. All samples were washed, air-dried, and were attached to aluminium stubs and then sputtered with a $200^{\circ} \mathrm{A}$ thick layer of gold under sputtering unit JEOL JFC-1600 (auto fine coater). SEM JEOL JSM-6390A with magnification going from $10 \times$ to $20,000 \times$ was used in the study.

\section{Statistical Analysis}

Data obtained for surface microhardness were analyzed using SPSS version 17.0. ANOVA, LSD post hoc test, and unpaired $t$-test with $p$ value $\leq 0.05$ were considered as significant.

\section{Results}

Results showed a significant difference between experimental groups ( $p<0.001$ ). Functionalized tricalcium phosphate paste shows significantly higher increase in mean microhardness than CPP-ACPF and control group. The mean change in microhardness in the CPP-ACPF group was significantly higher than the control group for both permanent and primary enamel specimen. Also, ANOVA ( $F$ ) showed significant difference between microhardness values at different time intervals $(p<0.001)$. At 10 days and 5 days, microhardness values were significantly higher than baseline
(Tables 1 and 2). When pairwise comparison was done using the LSD post hoc test (Tables 3 and 4), it shows that mean change in microhardness in the fTCP group was significantly higher than CPP-ACPF and control group both at 5th and 10th days. Also the mean change in microhardness in the CPP-ACPF group was significantly higher than the control group both at 5th and 10th days and this implies for both permanent and primary enamel specimens. The unpaired $t$-test (Table 5 ) showed that mean change in microhardness in permanent teeth was significantly higher than primary teeth on 5th day and between baseline and on 10th day for CPP-ACPF and f-TCP groups.

\section{Discussion}

The contemporary dental practice focuses more on preventive strategies rather than invasive treatment options preventing loss of natural tooth substance. Remineralization of noncavitated lesions represents a similar attempt to prevent disease progression and improve aesthetics, strength, and function. ${ }^{15}$ Although saliva has the ability to remineralize-demineralize enamel crystals, net remineralization produced by saliva is small due to the low ion concentration gradient from saliva into the lesion. ${ }^{16}$

Table 1: Mean and standard deviation of reduced surface microhardness in permanent tooth enamel specimens after cycling through a pH cycling model lasting 10 days

\begin{tabular}{llllrr}
\hline Groups & $V H N^{0}$ & $V H N^{5}$ & $\Delta V H N^{5}$ & \multicolumn{1}{c}{$V H N^{10}$} & \multicolumn{1}{c}{$\Delta V H N^{10}$} \\
\hline CPP-ACPF group & $40.06 \pm 2.02$ & $79.42 \pm 2.74$ & $39.36 \pm 3.52$ & $134.52 \pm 2.11$ & $94.46 \pm 3.20$ \\
f-TCP group & $39.24 \pm 1.51$ & $89.82 \pm 2.69$ & $50.58 \pm 3.13$ & $146.52 \pm 5.16$ & $107.38 \pm 6.12$ \\
Control group & $39.90 \pm 1.11$ & $57.69 \pm 4.05$ & $17.79 \pm 4.46$ & $62.40 \pm 3.04$ & $22.50 \pm 3.19$ \\
\hline
\end{tabular}

$\mathrm{VHN}^{0}=$ mean baseline Vickers hardness number, $\mathrm{VHN}^{5}=$ mean $\mathrm{VHN}$ after 5 days of cycling; $\Delta \mathrm{VHN}^{5}=$ difference between mean $\mathrm{VHN}^{5}$ and $\mathrm{VHN}^{0} ; \mathrm{VHN}^{10}=$ mean VHN after 10 days of cycling; $\triangle \mathrm{VHN}^{10}=$ difference between mean $\mathrm{VHN}^{10}$ and $\mathrm{VHN}^{0}$

Table 2: Mean and standard deviation of reduced surface microhardness in primary tooth enamel specimens after cycling through a pH cycling model lasting 10 days

\begin{tabular}{llllll}
\hline Groups & $V H N^{0}$ & $V H N^{5}$ & $\Delta V H N^{5}$ & $V H N^{10}$ & $\Delta V H N^{10}$ \\
\hline CPP-ACPF group & $31.24 \pm 2.59$ & $64.88 \pm 1.56$ & $33.64 \pm 1.81$ & $86.88 \pm 2.45$ & $55.64 \pm 4.17$ \\
f-TCP group & $32.52 \pm 2.20$ & $72.84 \pm 1.15$ & $40.32 \pm 2.36$ & $104.46 \pm 4.88$ & $71.94 \pm 4.09$ \\
Control group & $32.74 \pm 3.02$ & $51.46 \pm 1.98$ & $18.72 \pm 2.93$ & $58.60 \pm 1.90$ & $25.86 \pm 3.76$ \\
\hline
\end{tabular}

$\mathrm{VHN}^{0}=$ mean baseline Vickers hardness number, $\mathrm{VHN}^{5}=$ mean $\mathrm{VHN}$ after 5 days of cycling; $\Delta \mathrm{VHN}^{5}=$ difference between mean $\mathrm{VHN}^{5}$ and $\mathrm{VHN}^{0} ; \mathrm{VHN}^{10}=$ mean $\mathrm{VHN}$ after 10 days of cycling; $\triangle \mathrm{VHN}^{10}=$ difference between mean $\mathrm{VHN}^{10}$ and $\mathrm{VHN}^{0}$

Table 3: Pairwise comparison of change in microhardness in different experimental groups of permanent teeth using LSD post hoc test

\begin{tabular}{|c|c|c|c|}
\hline $\begin{array}{l}\text { Comparison } \\
\text { groups }\end{array}$ & $\Delta V H N^{5}$ & $\Delta V H N^{10}$ & $p$ value \\
\hline $\begin{array}{l}\text { CPP-ACPF } \\
\text { paste and fTCP } \\
\text { paste }\end{array}$ & -11.22 & -12.92 & $0.000(\mathrm{~S})$ \\
\hline $\begin{array}{l}\text { CPP-ACPF } \\
\text { paste and } \\
\text { control }\end{array}$ & 21.57 & 71.96 & $0.000(S)$ \\
\hline $\begin{array}{l}\text { fTCP paste and } \\
\text { control }\end{array}$ & 32.79 & 84.88 & $0.000(\mathrm{~S})$ \\
\hline \multicolumn{4}{|c|}{$\begin{array}{l}\mathrm{VHNO}=\text { mean baseline Vickers hardness number, } \mathrm{VHN}^{5}=\text { mean } \mathrm{VHN} \text { after } \\
5 \text { days of cycling; } \triangle \mathrm{VHN}^{5}=\text { difference between mean } \mathrm{VHN}^{5} \text { and } \mathrm{VHN}^{0} \text {; } \\
\mathrm{VHN}^{10}=\text { mean } \mathrm{VHN} \text { after } 10 \text { days of cycling; } \Delta \mathrm{VHN}^{10}=\text { difference between } \\
\text { mean } \mathrm{VHN}^{10} \text { and } \mathrm{VHN} \\
\mathrm{S} \text { and NS indicate significant difference and nonsignificant difference }\end{array}$} \\
\hline
\end{tabular}

Table 4: Pairwise comparison of change in microhardness in different experimental groups of primary teeth using LSD post hoc test

\begin{tabular}{|c|c|c|c|}
\hline $\begin{array}{l}\text { Comparison } \\
\text { groups }\end{array}$ & $\Delta V H N^{5}$ & $\Delta V H N^{10}$ & $p$ value \\
\hline $\begin{array}{l}\text { CPP-ACPF } \\
\text { paste and fTCP } \\
\text { paste }\end{array}$ & -7.96 & -17.58 & $0.000(\mathrm{~S})$ \\
\hline $\begin{array}{l}\text { CPP-ACPF } \\
\text { paste and } \\
\text { control }\end{array}$ & 13.42 & 28.28 & $0.000(\mathrm{~S})$ \\
\hline $\begin{array}{l}\text { fTCP paste and } \\
\text { control }\end{array}$ & 21.38 & 45.86 & $0.000(\mathrm{~S})$ \\
\hline \multicolumn{4}{|c|}{$\begin{array}{l}\mathrm{VHN}^{0}=\text { mean baseline Vickers hardness number, } \mathrm{VHN}^{5}=\text { mean } \mathrm{VHN} \text { af- } \\
\text { ter } 5 \text { days of cycling; } \triangle \mathrm{VHN} \mathrm{N}^{5}=\text { difference between mean } \mathrm{VHN}^{5} \text { and } \mathrm{VHN}^{0} \text {; } \\
\mathrm{VHN}^{10}=\text { mean } \mathrm{VHN} \text { after } 10 \text { days of cycling; } \triangle \mathrm{VHN}^{10}=\text { difference between } \\
\text { mean } \mathrm{VHN}^{10} \text { and } \mathrm{VHN} \mathrm{N}^{0} \\
\mathrm{~S} \text { and NS indicate significant difference and nonsignificant difference }\end{array}$} \\
\hline
\end{tabular}


Remineralization Potential of f-TCP and CPP-ACPF Paste on Artificial White Spot Lesion

Table 5: Unpaired $t$-test for comparison of change in microhardness between permanent and primary samples of different groups at 5 and 10 days

\begin{tabular}{|c|c|c|c|c|c|c|}
\hline \multirow[b]{2}{*}{ Groups } & \multicolumn{3}{|c|}{5 days $\left(\triangle V H N^{5}\right)$} & \multicolumn{3}{|c|}{10 days $\left(\triangle V H N^{10}\right)$} \\
\hline & $t$ test value & $D f$ & $p$ value & t test value & $D f$ & $p$ value \\
\hline CPP-ACPF group & 3.235 & 08 & $0.012(S)$ & 16.500 & 08 & $0.000(\mathrm{~S})$ \\
\hline f-TCP group & 5.847 & 08 & $0.000(S)$ & 10.769 & 08 & $0.000(\mathrm{~S})$ \\
\hline Control group & -0.389 & 08 & 0.707 (NS) & -1.524 & 08 & 0.166 (NS) \\
\hline
\end{tabular}

$\mathrm{VHN}^{0}=$ mean baseline Vickers hardness number, $\mathrm{VHN}^{5}=$ mean $\mathrm{VHN}$ after 5 days of cycling; $\Delta \mathrm{VHN}^{5}=$ difference between mean $\mathrm{VHN}^{5}$ and $\mathrm{VHN}^{0} ; \mathrm{VHN}^{10}=$ mean VHN after 10 days of cycling; $\triangle \mathrm{VHN}^{10}=$ difference between mean $\mathrm{VHN}^{10}$ and $\mathrm{VHN}^{0}$

$S$ and NS indicate significant difference and nonsignificant difference

Although fluoride is used as the first line of treatment in case of white spot lesion, but its capacity to promote remineralization is hindered by the presence of calcium and phosphate ions. ${ }^{17}$ To prevail over this incompatibility of these three ions, two technologies have been developed: CPP-ACP (casein phosphopeptide stabilized amorphous calcium phosphate) marketed as Tooth Mousse and CPP-ACPF (containing CPP-ACP plus 900 ppm F) as MI Paste Plus.

Fluoride when added to CPP-ACP synergistically remineralizes early carious lesion. Enzymes present in plaque named as phosphatase and peptidases partially degrade CPP-based products, which results in increased $\mathrm{pH}$ due to the liberation of ammonia. However, when fluoride is added to CPP, it hinders phosphatase activity by prolonging the action of molecular complexes. ${ }^{18} \mathrm{CPP}$ ACPF renders all the elements necessary for dental remineralization on the surface of the tooth and in dental biofilm. This provides remineralization with formation of fluorapatite, which is more resilient to future acid challenge. ${ }^{19}$

Functionalized tricalcium phosphate has been incorporated in the tooth crème with sodium fluoride and comes under the brand name of Clinpro tooth crème ( $3 \mathrm{M} \mathrm{ESPE).} \mathrm{According} \mathrm{to} \mathrm{the}$ manufacturer, it acts as a precursor for hydroxyapatite formation; it is highly biocompatible as well as bioactive and it also manifests lattice defects, which allows for crystal modification. ${ }^{20}$ Clinpro is manufactured by the milling technique by fusing it with sodium lauryl sulfate so that calcium oxides do not come in contact with fluoride, which could render both of them inefficient. When Clinpro comes into contact with the dental surface that is moistened by saliva, the protective barrier breaks down and thus making fluoride ions, calcium, and phosphate available to the teeth. ${ }^{21}$

The best way to replicate the oral environment in vitro is by exposing specimens to $\mathrm{pH}$-cycling models, which are equivalent to dynamics of tooth decay. ${ }^{22}$ Tooth specimens were exposed to demineralizing solution containing a weak acid $(\mathrm{pH}=5.0)$ of $0.1 \mathrm{M}$ lactic acid and $0.2 \%$ polyacrylic acid (Carbopol C907) $50 \%$ saturated with hydroxyapatite as previously professed by White. ${ }^{23}$ A lactate buffer was used to produce artificial caries lesions due to the fact that this acid represents $90 \%$ or more of the sucrose and/or glucose fermented by streptococci. Polyacrylic acid was used because it's an excellent surface protector. It enables the organic acids to diffuse through the surface zone, generating a subsurface lesion and which is morphologically similar to the pathological carious lesion. ${ }^{24}$

Specimens were kept in the demineralization solution for 4 hours to simulate the drop in $\mathrm{pH}$ that occurs after ingestion of fermentable carbohydrates and which is capable of initiating and replicating the caries process. ${ }^{25}$ Artificial saliva as storage media was used to simulate the oral condition. ${ }^{26}$

The present study compared the change in microhardness following treatment with CPP-ACPF and f-TCP over 10 days. Baseline surface microhardness (of the white spot lesion) achieved was $37.50-42.60$ for permanent teeth, which is similar to a study done by Karlinsey et al. ${ }^{14}$ and was $28.90-35.10$ for primary teeth. This difference in hardness in primary and permanent is due to different microchemical structure of the two. Primary teeth have greater susceptibility to dissolution as they are less mineralized comparatively. The diffusion coefficient is greater and the overall mineral density is lower in the outermost layers of the primary enamel. ${ }^{27}$

The literature states that microhardness of enamel after 10 days application of $\mathrm{f}-\mathrm{TCP}+500$ ppm of fluoride increases by $106.2 \pm 7.4$ VHN. ${ }^{14,25,28}$ Another study comparing dentifrice containing 5000 ppm fluoride with Clinpro 5000 (5000 ppm fluoride + fTCP) showed a mean increase of $105.6 \pm 5.6 \mathrm{VHN} .{ }^{29}$ After 10 days of treatment, the current study depicted a significant mean increase $(p<0.001)$ for both the enamel samples treated with f-TCP, which quantified to $107.38 \pm 6.12$ for permanent teeth (Table 1) and $71.94 \pm 4.09$ for primary teeth (Table 2). While for CPP-ACPF it was $94.46 \pm$ 3.20 (Table 1) for permanent teeth and $55.64 \pm 4.17$ (Table 2) for primary teeth.

The SEM images of untreated enamel like other studies ${ }^{30}$ showed intact enamel and smooth surface with sparse scratches. The SEM images of a white spot lesion show interprismatic dissolution of the enamel (Fig. 1). Also enhanced porosity and prism irregularity with exposed underlying perikymata and deepened Tomes' process pits were seen. According to Holmen et al., ${ }^{31}$ these accentuations of developmental features characterize an initial stage of enamel dissolution due to the carious process.

According to a study done by Chen et al., ${ }^{32}$ the white spot lesion can be classified in four types according to SEM observations: (1) areas of intact enamel, (2) focal holes, (3) prismatic pattern of dissolution, and (4) irregular pattern of dissolution. The pattern of dissolution, in the majority of the surfaces, was classified as type II; however, in primary enamel this pattern is considered to be greatly altered by the presence of aprismatic enamel. ${ }^{33}$

Although adequate remineralization and reduction in porosity are visible on treatment with CPP-ACPF, but treatment with $\mathrm{f}-\mathrm{TCP}$ resulted in an intensified remineralization throughout the surface. At a magnification of 5,000 $\times$, globular agglomerates were observed in the surface layer, which varied in size in different areas accompanied with prism etch pits filled globules (Fig. 1). The literature reports the significant remineralization effect of stimulated saliva because its calcium, phosphate, and fluoride content owns a reparative effect. ${ }^{34}$ The SEM images of the control group in the present study showed no evidence of adequate remineralization when compared to treatment groups and it seemed to retain the irregularities and porosities produced by etching. Remineralization could be appreciated more in the permanent enamel. This is because of the variation in primary and permanent enamel ranging from porosity due to lower content of phosphorus and calcium phosphate and also due to less organized crystals in primary enamel. ${ }^{35}$ 


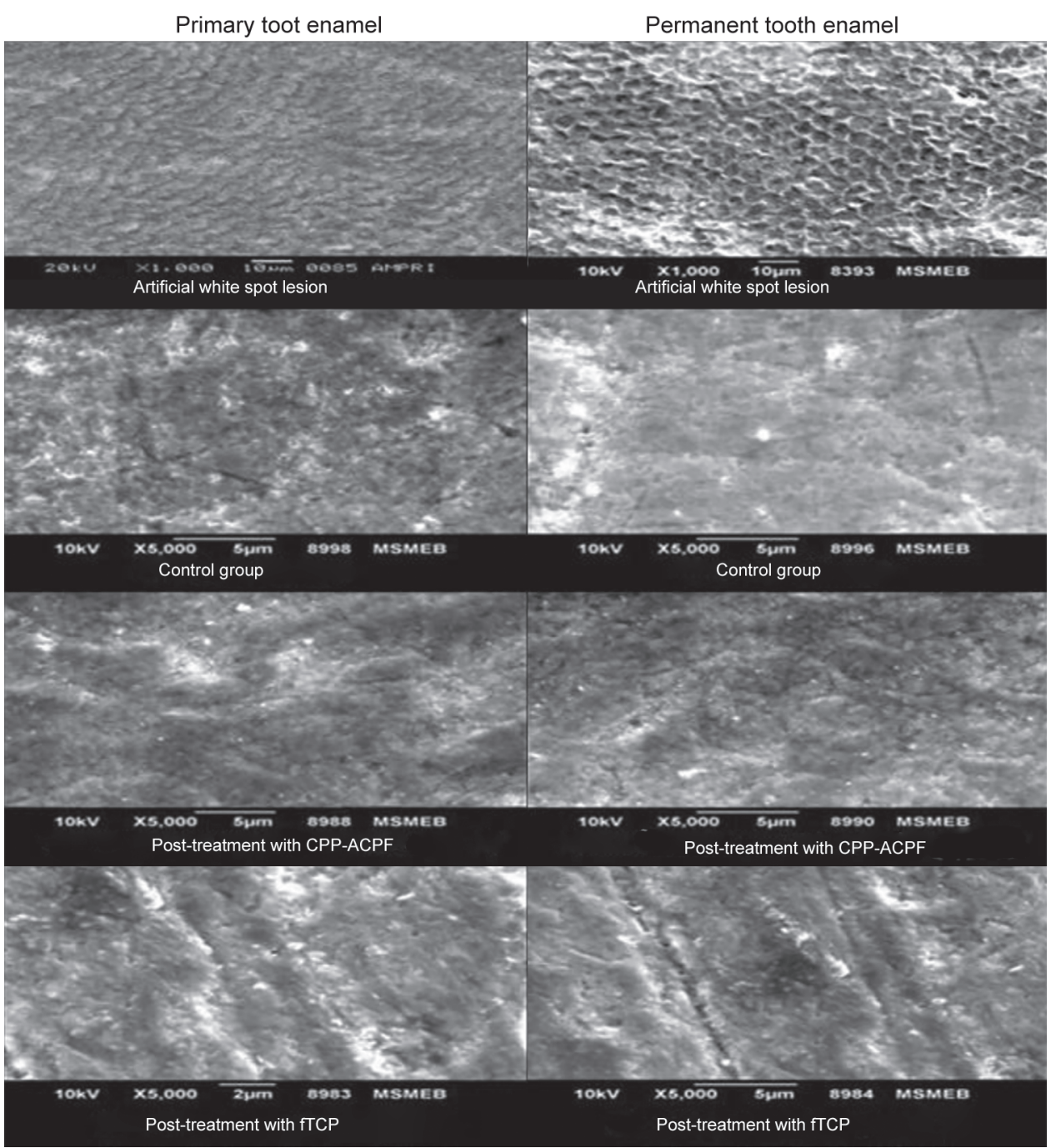

Fig. 1: The SEM image of primary and permanent enamel

Based on the results of our study, f-TCP showed comparatively more remineralization potential than CPP-ACPF. This result is similar to a previous study reporting low levels of available fluoride from MI Paste Plus (CPP-ACPF) because this product is highly thick in consistency and does not easily liquefy. ${ }^{13}$

\section{Conclusion}

In the current study, it was observed that f-TCP showed comparatively more remineralization potential than CPP-ACPF when applied for treating white spot lesions. Functionalized tricalcium phosphate can be suggested as an effective material for clinical use in minimally invasive dentistry due to its potential remineralization properties and also due to easy availability and economical nature.

\section{Clinical Significance}

The current study suggests that in cases of incipient lesions, choice of treatment could be noninvasive methods like remineralization with the use of fluoride ions, calcium, and phosphate, which can restore the defected and demineralized tissue, thus preserving the natural enamel tissue.

\section{References}

1. Cochrane NJ, Cai F, Huq NL, et al. New approaches to enhanced remineralization of tooth enamel. J Dent Res 2010;89(11):1187-1197. DOI: $10.1177 / 0022034510376046$.

2. Hellwig $E$, Altenburger M, Attin T, et al. Remineralization of initial carious lesions in deciduous enamel after application of dentifrices of different fluoride concentrations. Clin Oral Investig 2010;14(3):265. DOI: 10.1007/s00784-009-0290-4.

3. Madan N, Madan N, Sharma V, et al. Tooth remineralization using bioactive glass - a novel approach. J Acad Adv Dent Res 2011;2(2):56-59. DOI: $10.1177 / 2229411220110209$.

4. Elsayad I, Sakr A, Badr Y. Combining casein phosphopeptideamorphous calcium phosphate with fluoride: synergistic remineralization potential of artificially demineralized enamel or not? J Biomed Opt 2009;14(4):044039. DOI: 10.1117/1.3210780.

5. Pfarrer AM, Karlinsey R. Challenges of implementing new remineralization technologies. Adv Dent Res 2009;21(1):79-82. DOI: $10.1177 / 0895937409335643$.

6. Arends J, ten Bosch JJ. Review. demineralization and remineralization evaluation techniques. J Dent Res 1992;71(Spec No):924-928. DOI: 10.1177/002203459207100S27.

7. Gerould $\mathrm{CH}$. Electron microscope study of the mechanism of a fluorine deposition in teeth. J Dent Res 1945;24(5):223-233. DOI: 10.1177/00220345450240050201. 
8. Lata S, Varghese NO, Varughese JM. Remineralization potential of fluoride and amorphous calcium phosphate-casein phospho peptide on enamel lesions: an in vitro comparative evaluation. J Conserv Dent 2010;13(1):42-46. DOI: 10.4103/0972-0707.62634.

9. Lolayekar NV, Bhat V, Sham S, et al. Disinfection methods of extracted human teeth. JOHCD 2007;1(2):45-49. DOI: 10.5005/johcd1-2-27.

10. Moura JS, Rodrigues LK, Del Bel Cury AA, et al. Influence of storage solution on enamel demineralization submitted to $\mathrm{pH}$ cycling. J Appl Oral Sci 2004;12(3):205-208. DOI: 10.1590/S1678-77572004000300008.

11. Jabbarifar SE, Salavati S, Akhavan A, et al. Effect of fluoridated dentifrices on surface microhardness of the enamel of deciduous teeth. Dent Res J (Isfahan) 2011;8(3):113-117.

12. Ten Cate JM, Timmer K, Shariati M, et al. Effect of timing of fluoride treatment on enamel de- and remineralization in vitro: a pH-cycling study. Aries 1988;22(1):20-26.

13. Karlinsey RL, Mackey AC, Stookey GK. In vitro remineralization efficacy of Naf systems containing unique forms of calcium. Am J Dent 2009;22(3):185-188.

14. Karlinsey RL, Mackey AC, Walker TJ, et al. In vitro remineralization of human and bovine white-spot enamel lesions by NaF dentifrices: a pilot study. J Dentis Oral Hygiene 2011;3(2):22-29.

15. Tung MS, Eichmiller FC. Amorphous calcium phosphates for tooth mineralization. Compend Contin Educ Dent 2004;25(9 Suppl 1): S9-S13.

16. Silverstone $L M$. Remineralization of human enamel in vitro. Proc $R$ Soc Med 1972;65(10):906-908. DOI: 10.1177/003591577206501059.

17. Shen P, Manton DJ, Cochrane NJ, et al. Effect of added calcium phosphate on enamel remineralization by fluoride in a randomized controlled in situ trial. J Dent 2011;39(7):518-525. DOI: 10.1016/j. jdent.2011.05.002.

18. Vitorino R, Lobo MJ, Duarte JR, et al. The role of salivary peptides in dental caries. Biomed Chromatogr 2005;19(3):214-222. DOI: 10.1002/ bmc.438.

19. Gupta R, Prakash V.CPP-ACP complex as a new asdjunctive agent for remineralisation: a review. Oral Health Prev Dent 2011;9:151-165.

20. Karlinsey RL, Mackey AC. Solid-state preparation and dental application of an organically modified calcium phosphate. J Mater Sci 2009;44(1):346-349. DOI: 10.1007/s10853-008-3068-1.

21. Karlinsey RL, Mackey AC, Walker ER, et al. Spectroscopic evaluation of native, milled and functionalized $\beta$-TCP seeding into dental enamel lesions. J Mater Sci 2009;44(18):5013-5016. DOI: 10.1007/s10853-0093774-3.
22. Ten Cate JM, Duijsters PP. Influence of fluoride in solution on tooth demineralization. I. chemical data. Caries Res 1983;17(3):193-199. DOI: 10.1159/000260667.

23. WhiteDJ. Reactivity of fluoride dentifrices with artificial caries. I. Effects on early lesions: $F$ uptake, surface hardening and remineralization. Caries Res 1987;21(2):126-140. DOI: 10.1159/000261013.

24. de Marsillac MW, de Sousa Vieira R. Assessment of artificial caries lesions through scanning electron microscopy and cross-sectional microhardness test. Indian J Dent Res 2013;24(2):249-254. DOI: 10.4103/0970-9290.116699.

25. Faller RV, Eversole SL, Yan J. Anticaries potential of a stabilized stannous-containing sodium fluoride dentifrice. Am J Dent 2010;23:32B-38B.

26. Mahmoud HA, Elmayad DM, Ghandour IA. Effects of dental bleaching on caries resistance of human enamel. Cairo Dental Journal 2009;25(3):449-455.

27. Linden LA, Björkman S, Hattab F. The diffusion in vitro of fluoride and chlorhexidine in the enamel of human deciduous and permanent teeth. Arch Oral Biol 1986;31:33-37.

28. Karlinsey RL, Mackey AC, Stookey GK, et al. In vitro assessments of experimental $\mathrm{NaF}$ dentifrices containing a prospective calcium phosphate technology. Am J Dent 2009;22(3):180-184.

29. Karlinsey RL, Mackey AC, Walker ER, et al. Remineralization potential of 5,000 Ppm fluoride dentifrices evaluated in a pH cycling model Reference. J Dent Oral Hyg 2010;2(1):1-6.

30. Thylstrup A, Fredebo L. A method for studying surface coatings and the underlying enamel features in the scanning electron microscope Frank RM, Leach SA. Surface and colloid phenomena in the oral cavity: methodological aspects. St. Louis: IRL Press; 1982. pp. 169-184.

31. Holmen L, Thylstrup A, Ogaard B, et al. In vivo a scanning electron microscopic study of progressive stages of enamel caries. Caries Res 1985;19(4):355-367. DOI: 10.1159/000260867.

32. Chen CC, Tuang ST, Chen HS, et al. Effect of lasers and floride on acid resistance of human enamel with incipient carious lesion. The Taiwan J Oral Med Sci 2009;25:23-34.

33. Silverstone LM, Dogon IL. The effect of phosphoric acid on human deciduous enamel surfaces in vitro. J Int Assoc Dent Child 1976;7:1115.

34. Mandel ID. The functions of saliva. J Dent Res 1987;66(2_suppl):623627. DOI: $10.1177 / 00220345870660 S 203$.

35. Badr SBY, Ibrahim MA. Protective effect of three different fluoride pretreatments on artificially induced dental erosion in primary and permanent teeth. J Am Sci 2010;6(11):442-451. 